\title{
Behavioural Responses in Stallions to a Novel Object
}

\author{
Silvana POPESCU ${ }^{*}$, Eva DIUGAN ${ }^{2}$, Daniela OROS $^{1}$, Caius A STEPAN ${ }^{1}$, Liana C DANCI ${ }^{1}$, Cristin BORDA $^{1}$ \\ ${ }^{1}$ Faculty of Veterinary Medicine, University of Agricultural Sciences and Veterinary Medicine, Manastur \\ Street, no. 3-5, 400372, Cluj-Napoca, Romania \\ ${ }^{2}$ Beclean Studfarm, The National Forest Administration Romsilva, Petricani Street, no. 9A, 023841, \\ Bucuresti, Romania \\ *corresponding author: silvana.popescu@usamvcluj.ro
}

Bulletin UASVM Veterinary Medicine 73(2) / 2016,

Print ISSN 1843-5270; Electronic ISSN 1843-5378

DOI:10.15835/buasvmcn-vm: 12174

\begin{abstract}
The aim of this study was to test the response towards a novel object in Lipizzaner and Romanian Draft stallions. In addition, we have investigated the effect of the object's colour on horses' behavioural response. The novel object test was performed in Lipizzaner $(n=11)$ and Romanian Draft $(n=8)$ stallions, in four different stages, observing the stallions during 45 minutes in each stage (15 minute/coloured ball), and assessing a series of behavioural indicators. The data was analyzed using the SPSS statistical software. There were no significant differences in the response of horses to the novel object in the three stages, or differences between the different breeds. An important result found was the absence of discrimination for colour differences - the stallions behaved similarly, irrespective to the colour of the ball. Based on the obtained results it can be concluded that stallions were receptive to the novel object, they showed interest for the balls, and these can be used to alleviate the monotony in the periods of individual housing in boxes.
\end{abstract}

Keywords: behavioural indicators, novel object test, stallions

\section{INTRODUCTION}

The way in which the horse reacts to novelty is crucial for safety of both horses and humans (Gorecka et al., 2007). Novel object tests are often used to test the horse's temperamental characteristics, to select the right horse for a specific rider and to assess welfare (Bulens et al., 2015). In our knowledge no such study was made until now in Romania.

\section{AIMS AND OBJECTIVES}

The aim of this study was to test the response towards a novel object in Lipizzaner and Romanian Draft stallions. In addition the effect of the object's colour on the behavioural response of horses was investigated.

\section{MATERIALS AND METHODS}

The novel object test was performed in Lipizzaner ( $\mathrm{n}=11)$ and Romanian Draft $(\mathrm{n}=8)$ stallions. The stallions were housed in individual boxes. The novel object was represented by balls of same dimensions and three different colours: white, red and green. The experiment was performed in four stages: analyzing the stallions' behaviour in their living environment, than introducing the balls of different colours, one by one, in the box of each stallion, in the other three stages, at two days interval. Each stallion was observed during 45 minutes in each stage (15 minute/coloured ball), assessing a series of behavioural indicators: the frequency of snuffling, neighing, facial expressions, the position of the ears, attitude and different ways to interact with the novel object. The data was analyzed using the SPSS statistical software. To compare the behavioural responses, the Mann-Whitney and Friedman tests were used. The value of minimal significance was considered at $\mathrm{P}<0.05$.

\section{RESULTS AND DISCUSSION}

In the first stage no nervousness or fear reaction was observed in the assessed stallions. The behavioural responses in the stallions of the two breeds to the novel objects for the three stages of the experiment are presented in Tab. 
Tab. 1. The behavioural responses of the Lipizzaner and Romanian Draft stallions in the novel object test in the three testing stages

\begin{tabular}{|c|c|c|c|c|c|c|}
\hline \multirow[t]{2}{*}{ Behaviouralindicators } & \multicolumn{3}{|c|}{ Lipizzaner $(n=11)$} & \multicolumn{3}{|c|}{ Romanian Draft $(n=8)$} \\
\hline & $\mathrm{WB}$ & $\mathrm{RB}$ & GB & $\mathrm{WB}$ & $\mathrm{RB}$ & $\mathrm{GB}$ \\
\hline \multicolumn{7}{|l|}{ Stage 2} \\
\hline Approaching (s) & 12.64 & 38.00 & 60.18 & 16.00 & 11.12 & 15.75 \\
\hline Touching (\%) & 100.00 & 81.82 & 81.82 & 100.00 & 100.00 & 87.5 \\
\hline Hitting (\%) & 36.36 & 36.36 & 27.27 & 25.00 & 25.00 & 62.5 \\
\hline Smelling (s) & 42.00 & 51.0 & 60.91 & 36.75 & 44.00 & 38.37 \\
\hline Vocalizing (no.) & 4.72 & 3.27 & 1.36 & 5.37 & 3.88 & 3.13 \\
\hline Flatting ears (\%) & 18.18 & 36.36 & 18.18 & 25.00 & 25.00 & 25.00 \\
\hline Alert face (\%) & 36.36 & 36.36 & 18.18 & 25.00 & 25.00 & 25.00 \\
\hline \multicolumn{7}{|l|}{ Stage 3} \\
\hline Approaching (s) & 13.45 & 7.18 & 5.36 & 11.75 & 8.75 & 6.75 \\
\hline Touching (\%) & 100.00 & 100.00 & 81.82 & 75.00 & 75.00 & 75.00 \\
\hline Hitting (\%) & 18.18 & 27.27 & 45.45 & 37.50 & 37.50 & 50.00 \\
\hline Smelling (s) & 34.00 & 59.64 & 24.36 & 57.50 & 46.25 & 78.00 \\
\hline Vocalizing (no.) & 3.91 & 3.00 & 0.72 & 2.00 & 3.25 & 2.37 \\
\hline Flatting ears (\%) & 27.27 & 18.18 & 0.00 & 25.00 & 0.00 & 0.00 \\
\hline Alert face (\%) & 27.27 & 18.18 & 0.00 & 25.00 & 37.50 & 0.00 \\
\hline \multicolumn{7}{|l|}{ Stage 4} \\
\hline Approaching (s) & 10.82 & 5.73 & 4.64 & 9.50 & 7.12 & 9.75 \\
\hline Touching (\%) & 100.00 & 100.00 & 72.73 & 100.00 & 75.00 & 100.00 \\
\hline Hitting (\%) & 18.18 & 18.18 & 27.27 & 25.00 & 25.00 & 25.00 \\
\hline Smelling (s) & 46.82 & 28.45 & 35.55 & 33.25 & 23.12 & 34.37 \\
\hline
\end{tabular}

1. No significant differences were found in the responses of horses to the novel object in the three stages, or between the different breeds. Regarding the reactivity of horses towards humans some studies found differences when compared different horse breeds, but these breeds were also found to display general temperamental differences (Skipper, 2007). On the other hand, it has to take into account the fact that the Romanian draft is a young breed, developed by crossing Ardennes stallions with local mares. Therefore, these animals can show temperamental traits of both breeds, and probably the influence of the same environmental factors on the animals in the studied farm. The results proved the absence of discrimination for the colour differences; the stallions behaved similarly, irrespective to the colour of the ball. This is similar to the results of other studies (Bulens et al., 2015; Christensen et al., 2008). Horses of both breeds were mostly vigilant and focused on the novel object in the first stage of the test, but after their interest decreased, in the same way as Gorecka et al. (2007) observed.

The lack of fear responses (vocalizations, flatted ears, and alert facies) in the last stage indicates the fact that stallions begun to get used with the novel object. The same reaction was observed in other studies also (McCall et al., 2006; Gorecka et al., 2007).

\section{CONCLUSION}

Based on the obtained results it can be concluded that stallions were receptive to the novel objects, they showed interest for the balls, and these can be used to alleviate the monotony in the periods of individual housing in boxes.

\section{REFERENCES}

1. Bulens A, Sterken H, Beirendoonck SV, Thielen JV, Driessen $B$ (2015). The use of different objects during a novel object test in stabled horses. J Vet Behav 10(1):54-58.

2. Christensen JW, Zharkikh T, Ladewig J (2008). Do horses generalise between objects during habituation? Appl Anim Behav Sci 114:509-520.

3. Gorecka A, Bakuniak M, Chruszczewski MH, Jezierski TA (2007). A note on the habituation to novelty in horses: handler effect. Anim Sci Pap Rep 25(3):143-152.

4. Mccall CA, Hall S, Mc Elhenney WH, Cummins KA (2006). Evaluation and comparison of four methods of ranking horses based on their reactivity. Appl Anim Behav Sci 96:115-127.

5. Skipper L (2007). Understanding horse behaviour. Skyhorse Publishing, New York, p.144 